\title{
Drought hastened Maya decline
}

\section{A prolonged dry period contributed to civilization's collapse.}

\section{Helen Shen}

08 November 2012

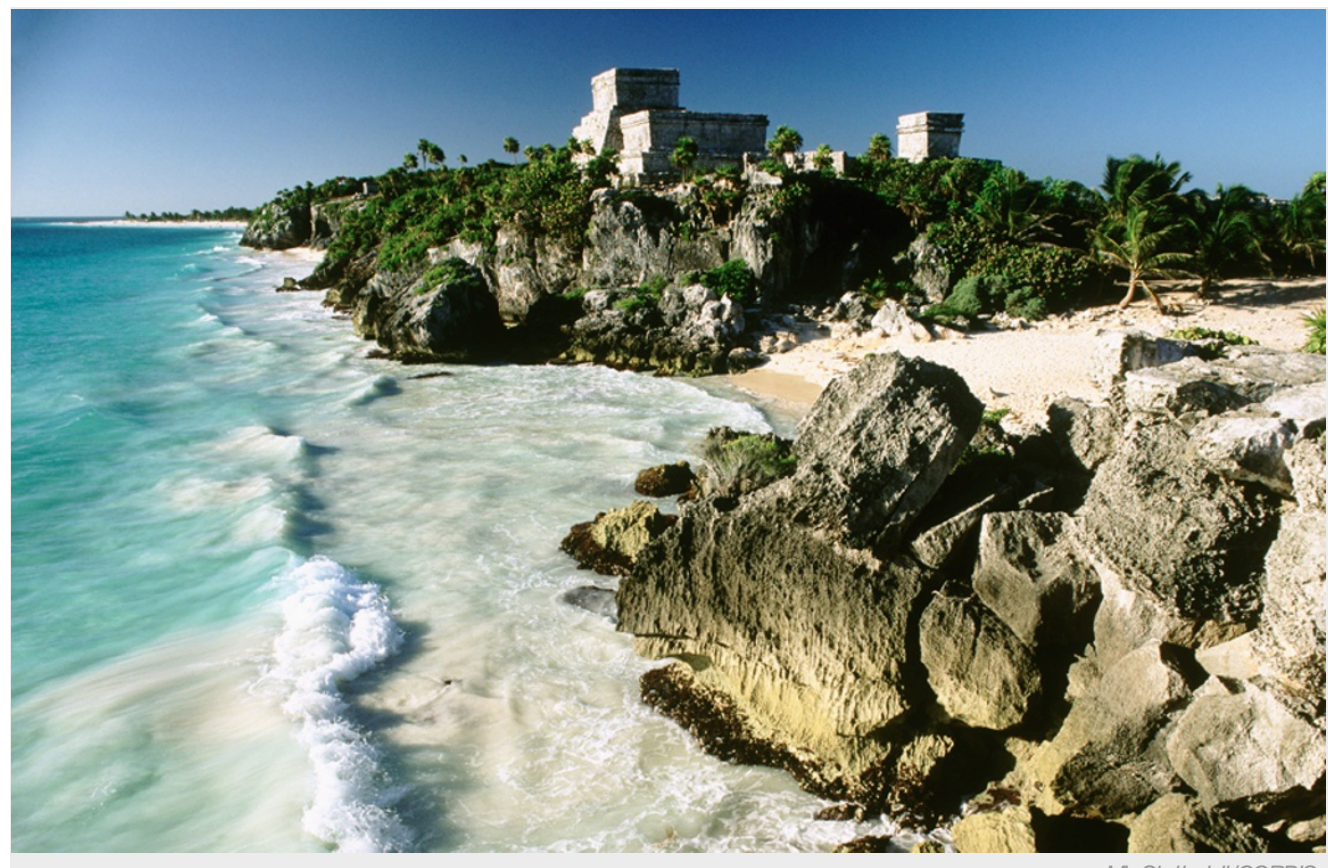

ML Sinibaldi/CORBIS

The Mayan civilization collapsed about 1,000 years ago, prehaps driven by extreme changes in climate.

The rapid decline of classic Maya civilization — which between 300 and 1000 ad occupied much of modern-day Mexico and Central America - has long puzzled archaeologists. No clear explanation has emerged for why the society, known for its sophisticated calendar system and pyramid construction, seemed to collapse between 800 and 1000 ad.

A study published today in Science ${ }^{1}$ now suggests that the Maya civilization was doomed by extreme changes in climate.

By analysing a 2,000-year-old stalagmite from a cave in southern Belize and studying archaeological records, palaeoclimatologist Douglas Kennett of Pennsylvania State University in University Park and his colleagues argue that unusual rainfall patterns shaped the fate of the Maya people ${ }^{1}$. Other researchers have proposed that dry climate conditions hastened the Maya collapse ${ }^{2,3}$, but the latest data provide one of the most complete and detailed rainfall records from the geographic centre of the Mayan territory.

The team estimated historical rainfall in the Mayan lowlands by measuring oxygen isotopes incorporated into the stalagmite from rainwater that seeped into the cave from the ground above. The precipitation levels were tied to specific dates by measuring the ratio of radioactive isotopes in the stalagmite.

"We're talking about a complex story, and we don't have all the details nailed at this point," says Kennett. He proposes that unusually high rainfall promoted a population boom between 440 and 660 ad. The stalagmite also pointed to protracted dry conditions between 660 and 1000 ad, which aligns with a period of political instability - reflected in a rapid proliferation of dated stone monuments erected by different rulers.

"I think one of the biggest contributions of this study is the real precision and accuracy of dating of this record," says David Hodell, a palaeoclimatologist at the University of Cambridge, UK, who presented some of the first data to support climate change as a factor in the Maya decline ${ }^{3}$. He marvelled at Kennett's error margins of 1-17 years - compared to about 100 years in many previous carbondating efforts. 
Many archaeologists say that the 'collapse' of the Maya civilization was probably a century-long crumble of many city states over a broad geographic region. "It would be a little bit dangerous to assume that this record was the key to climate change across the Maya world," says Jason Yaeger, an archaeologist at the University of Texas at San Antonio. He called the work "an important step forward" to inspiring similar projects at different sites throughout the region.

"I'm convinced drought had something to do with this," adds David Webster, a Pennsylvania State University anthropologist who was not involved in the study. However, he says, the relative rainfall inferred from the stalagmite should also be calibrated against actual recorded precipitation — which is available for the modern segment of the stalagmite.

David Stahle, a palaeoclimatologist at the University of Arkansas in Fayetteville, calls the stalagmite a "super-amazing" climate record, but is sceptical of the team's association of climate change with cultural records, but he says that the study could have important implications for climate modelling, because it adds to mounting evidence that extreme droughts - far exceeding those of modern experience - may have occurred more than 1,000 years ago.

"It demands explanation," says Stahle. "Will anthropogenic climate change return us to a regime like that?"

Nature I doi:10.1038/nature.2012.11780

\section{References}

1. Kennett, D. J. et al. Science advance online publication http://dx.doi.org/10.1126/science.1226299 (2012).

2. Medina-Elizalde, M. \& Rohling, E. J. Science 335, 956-959 (2012).

3. Hodell, D. A., Curtis, J. H. \& Brenner, M. Nature 375, 391-394 (1995). 